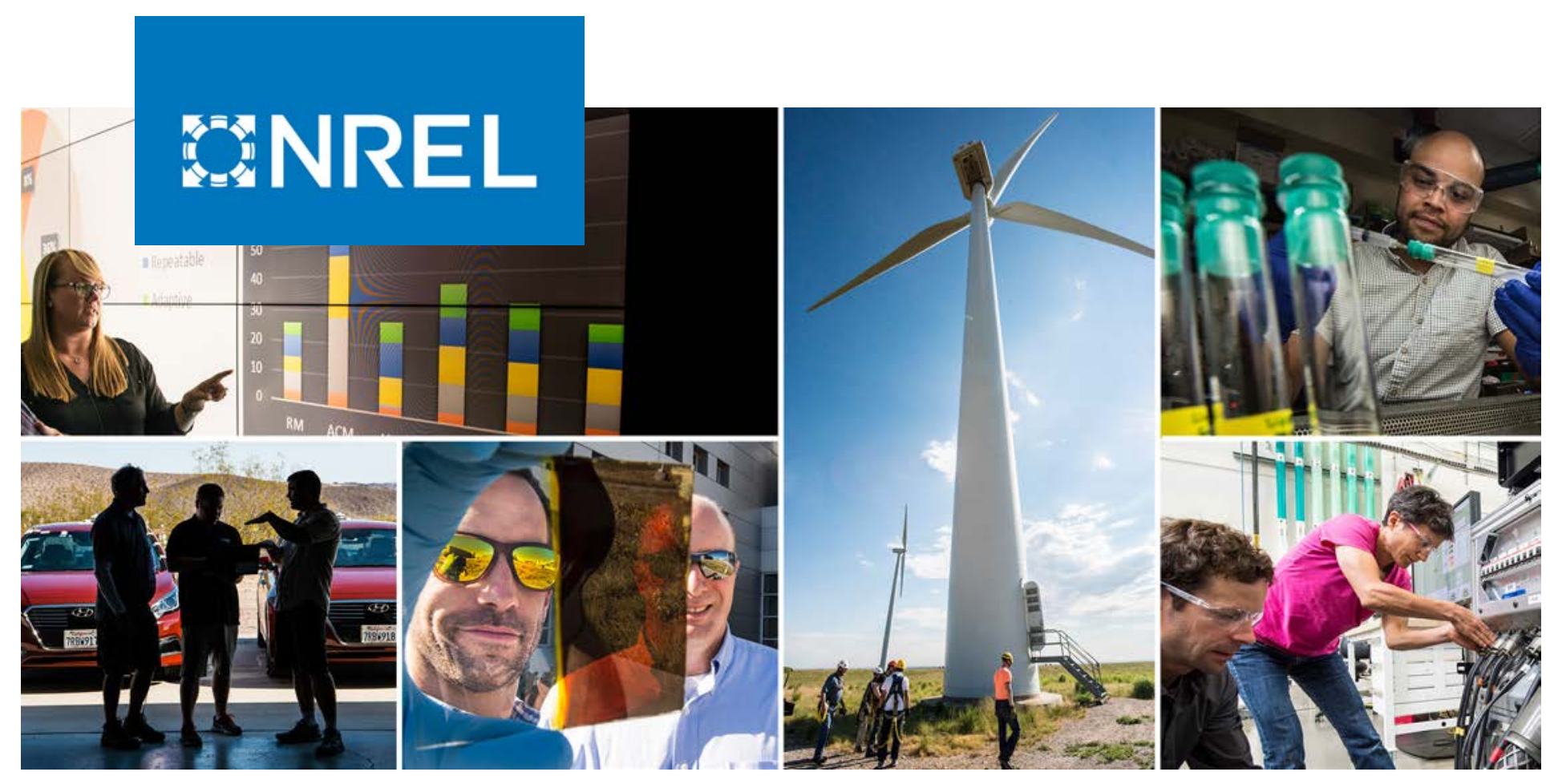

\title{
A Guide to Implementing Concentrating Solar Power in Production Cost Models
}

Jennie Jorgenson, Matthew O'Connell, Paul Denholm, Janna Martinek, and Mark Mehos

National Renewable Energy Laboratory

NREL is a national laboratory of the U.S. Department of Energy

Office of Energy Efficiency \& Renewable Energy

Operated by the Alliance for Sustainable Energy, LLC

This report is available at no cost from the National Renewable Energy Laboratory (NREL) at www.nrel.gov/publications.
Technical Report

NREL/TP-6A20-68527

December 2018 


\section{GNREL}

\section{A Guide to Implementing Concentrating Solar Power in Production Cost Models}

Jennie Jorgenson, Matthew O'Connell, Paul Denholm, Janna Martinek, and Mark Mehos

National Renewable Energy Laboratory

\section{Suggested Citation}

Jorgenson, Jennie, Matthew O'Connell, Paul Denholm, Janna Martinek, and Mark Mehos. 2018. A Guide to Implementing Concentrating Solar Power in Production Cost Models.

Golden, CO: National Renewable Energy Laboratory. NREL/TP-6A20-68527.

https://www.nrel.gov/docs/fy19osti/68527.pdf.

NREL is a national laboratory of the U.S. Department of Energy Office of Energy Efficiency \& Renewable Energy Operated by the Alliance for Sustainable Energy, LLC

This report is available at no cost from the National Renewable Energy Laboratory (NREL) at www.nrel.gov/publications.

Contract No. DE-AC36-08GO28308
Technical Report

NREL/TP-6A20-68527

December 2018

National Renewable Energy Laboratory 15013 Denver West Parkway Golden, CO 80401

303-275-3000 • www.nrel.gov 


\section{NOTICE}

This work was authored by the National Renewable Energy Laboratory, operated by Alliance for Sustainable Energy, LLC, for the U.S. Department of Energy (DOE) under Contract No. DE-AC36-08GO28308. Funding provided by the U.S. Department of Energy Office of Energy Efficiency and Renewable Energy. The views expressed herein do not necessarily represent the views of the DOE or the U.S. Government.

This report is available at no cost from the National Renewable Energy Laboratory (NREL) at www.nrel.gov/publications.

U.S. Department of Energy (DOE) reports produced after 1991 and a growing number of pre-1991 documents are available free via www.OSTI.gov.

Cover Photos by Dennis Schroeder: (clockwise, left to right) NREL 51934, NREL 45897, NREL 42160, NREL 45891, NREL 48097, NREL 46526.

NREL prints on paper that contains recycled content. 


\section{Abstract}

Concentrating solar power (CSP) is a unique form of renewable energy because it can be integrated with thermal energy storage (TES). CSP-TES can provide value to the power grid by supplying a dispatchable source of renewable energy and potentially other grid services such as operating reserves. These characteristics of CSP-TES are often incompletely captured in utility-planning or technology-valuation analyses. We describe an approach for representing the dispatchability of CSP-TES accurately in production cost models while still considering the resource-dependent nature of the technology. We also discuss the challenge of properly representing the ability of CSP-TES to provide operating reserves because of the technology's energy-limited nature. We apply our modeling methods to illustrate how the value of providing dispatchable energy and ancillary services can be captured together and independently. This approach can be applied to most commercial, academic, and open-source production cost models to value CSP-TES appropriately in power system planning studies. 


\section{Table of Contents}

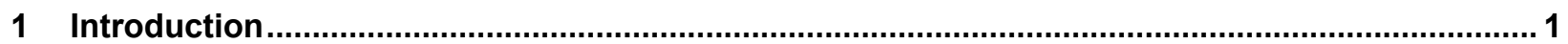

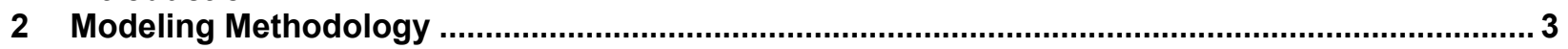

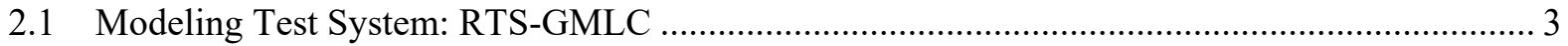

2.2 General Approach to Incorporating CSP-TES in a Production Cost Model ............................... 4

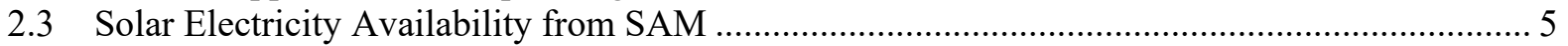

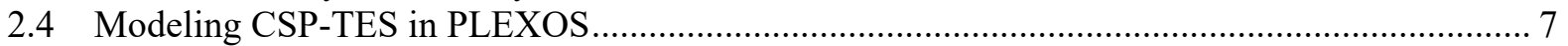

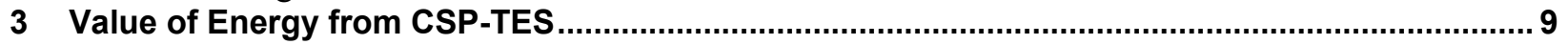

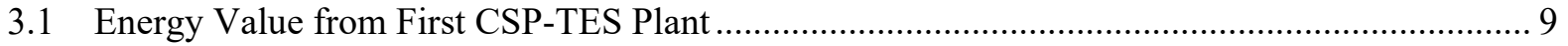

3.2 Energy Value from Additional CSP-TES Capacity ….......................................................... 9

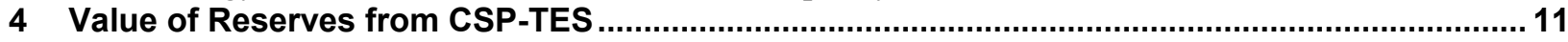

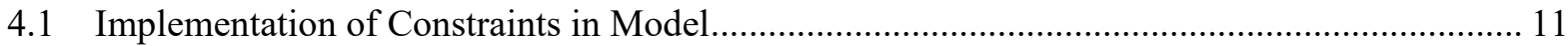

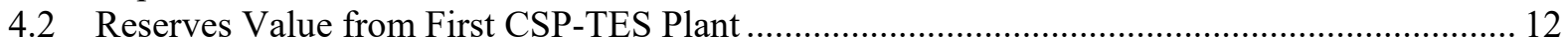

4.3 Reserves Value from Additional CSP-TES Capacity .......................................................... 14

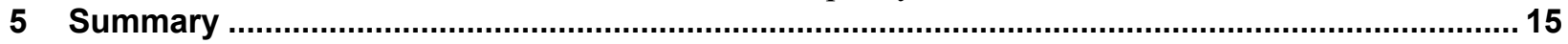

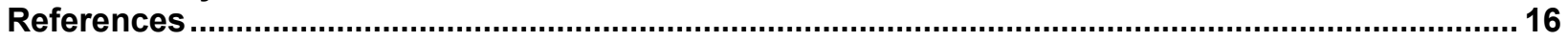




\section{List of Figures}

Figure 1. Dispatch of RTS-GMLC test system used in this analysis, for four days in the

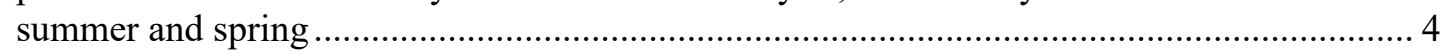

Figure 2. Generalized method for incorporating CSP-TES in a production cost model............................ 5

Figure 3. Four components of an indirect molten salt CSP-TES plant ..................................................... 6

Figure 4. Optimized CSP-TES dispatch from the PLEXOS model ........................................................ 9

Figure 5. Decrease in energy value of CSP-TES with subsequent additions of capacity ......................... 10

Figure 6. Displacement of generation mix by CSP-TES changes with each capacity addition.................. 10

Figure 7. Energy and ancillary service dispatch for CSP-TES plant as determined by PLEXOS model... 13

Figure 8. Decreases in value of reserve services provided by CSP-TES with subsequent addition of

\section{List of Tables}

Table 1. Generator Capacity and Peak Load in the RTS-GMLC System............................................... 3 


\section{Introduction}

Electricity from solar energy is produced either through photovoltaic (PV) conversion or through concentrating solar power (CSP). Unlike PV, which directly converts sunlight into electricity, CSP systems use a field of mirrors to focus sunlight onto a receiver, generating intense heat that can be used to drive a thermodynamic cycle [1]. While today's CSP systems are typically integrated with steam-Rankine power blocks, next-generation systems are being designed to provide thermal energy to advanced supercritical carbon dioxide cycles operating at efficiencies greater than $50 \%[2]$.

The number of worldwide solar energy installations is expected to continue increasing into the foreseeable future [3]. Over the past five years, worldwide capacity of CSP has tripled to nearly five gigawatts (GW) [4]. Although the cost of CSP has not dropped as dramatically as the cost of $\mathrm{PV}$ in recent years, there are indications CSP is beginning to decrease as well [5]. One major benefit of CSP technology is its ability to be coupled with thermal energy storage (TES) systems to create a dispatchable resource. This ability to control generator output allows CSP with TES (CSP-TES) to generate energy at more valuable times, provide firm system capacity, and potentially provide operating reserve services to the grid, all of which can increase the economic prospects of the technology [6-9].

The actual value of CSP-TES to the grid depends in part on the timing of the power plant operation, including allocation of capacity to energy and ancillary services. Previous analysis has demonstrated how optimizing CSP-TES dispatch against historical prices can increase revenue to a power plant operator [10-14]. Although such price-taker analysis can be useful, utility system planning typically requires an understanding of how all generators in a system will interact. Price-taker analyses assume the addition of a new plant, such as CSP-TES, will not affect system dynamics. In addition, price-taker tools use historical prices, which do not necessarily reflect how changing fuel prices and generator fleets will affect prices into the future. For this reason, planning studies typically use production cost models to evaluate different scenarios of generator mixes, fuel costs, and policies to determine life-cycle costs, emissions, and other factors relevant to policymakers and stakeholders [15]. Historically, production cost models have had limited treatment of CSP-TES, and few studies thoroughly examine the value of CSP-TES relative to other resources using these tools [16]. However, recently published studies do attempt to quantify the value CSP-TES based on the displacement of conventional generation using production cost modeling tools $[7,8,17,18]$. These studies encompass a variety of current and future scenarios for fuel prices, generator fleets, and renewable penetration levels, including locations in the western United States, Australia, and northern Africa. However, only one of these studies [18] presents a thorough method for modeling CSP-TES, and none of them presents the methodology for modeling CSP-TES in providing ancillary services.

In this work, we discuss a method to implement CSP-TES in production cost model (PCM) planning tools. The approach detailed here can be applied to most commercial, academic, and open-source PCMs to properly represent the dispatchable and yet energy-limited nature of CSPTES. First, we describe a two-step process that first uses a publicly available model to simulate the CSP-TES solar field and generates an hourly energy inflow that is then used by the PCM to co-optimize provision of energy and ancillary services at the system level. This allows for an 
equitable comparison of CSP-TES with other generation resources, enables an evaluation of different CSP-TES design configurations, and can help determine the value of providing various services, including operating reserves. We then show the results of a case study using a test system to estimate the value of CSP-TES for providing energy and ancillary services. We also demonstrate how this approach can be used to evaluate the addition of multiple plants, which is one of many types of analysis that cannot be performed with price-taker analysis.

The remainder of this report is organized as follows. Section 2 discusses the two-part modeling methodology, Section 3 implements the methodology to quantify the operational value of energy from CSP-TES, and Section 4 evaluates the value of CSP-TES for providing ancillary services. 


\section{Modeling Methodology}

The operation of the electric power grid on an hourly or subhourly timescale presents a challenge in minimizing generation costs while maintaining reliability and adhering to many types of physical and institutional constraints. Production cost models, such as the commercially available PLEXOS software, simulate the commitment and dispatch of the power plant fleet to meet demand at every time step [19]. We use a test system in PLEXOS to demonstrate our approach and provide a test case to model the operational value of CSP-TES. Throughout this report, we describe implementation in PLEXOS, but our method should be applicable to any PCM that can simulate limited energy resources such as conventional hydroelectric plants.

\subsection{Modeling Test System: RTS-GMLC}

Production cost models require many types of input data, including generator parameters, network topology, and time-varying profiles such as electric demand and the weather-dependent generation patterns of solar and wind resources. We adopt the network and generator data from the RTS-GMLC model, a test case developed by the National Renewable Energy Laboratory (NREL) under the Grid Modernization Laboratory Consortium (GMLC) in 2017 [20]. This version of the system comprises 73 nodes, 121 lines, and 125 generators, including wind and PV generators. Table 1 shows the generator mix and peak load from the modeled system. The hourly wind, PV, and load data represent the resources of an area in the southwestern United States and are derived from the meteorology of 2006. These profiles have been used in multiple gridintegration studies [21, 22]. The fuel prices are \$2.1/MMBtu for coal, \$3.9/MMBtu for natural gas, $\$ 0.8 / \mathrm{MMBtu}$ for uranium, and $\$ 10.3 / \mathrm{MMBtu}$ for oil. Figure 1 shows an example of a dispatch stack illustrating the generation mix for four days in spring and summer. The figure indicates a coal-heavy system with intermediate gas and hydro plants, as well as gas and oil peaker plants.

Table 1. Generator Capacity and Peak Load in the RTS-GMLC Test System

\begin{tabular}{lc}
\hline Generator Type & Capacity (MW) \\
\hline Coal & 2,320 \\
Non-dispatchable hydro & 1,000 \\
Natural gas combined-cycle & 3,550 \\
Natural gas combustion turbine & 1,490 \\
Nuclear & 400 \\
Oil (combustion turbine and steam) & 324 \\
Wind & 862 \\
PV (utility scale) & 434 \\
PV (distributed rooftop) & 751 \\
\hline Total & $\mathbf{1 1 , 1 0 0}$ \\
Peak System Load & $\mathbf{8 , 2 5 0}$ \\
\hline
\end{tabular}




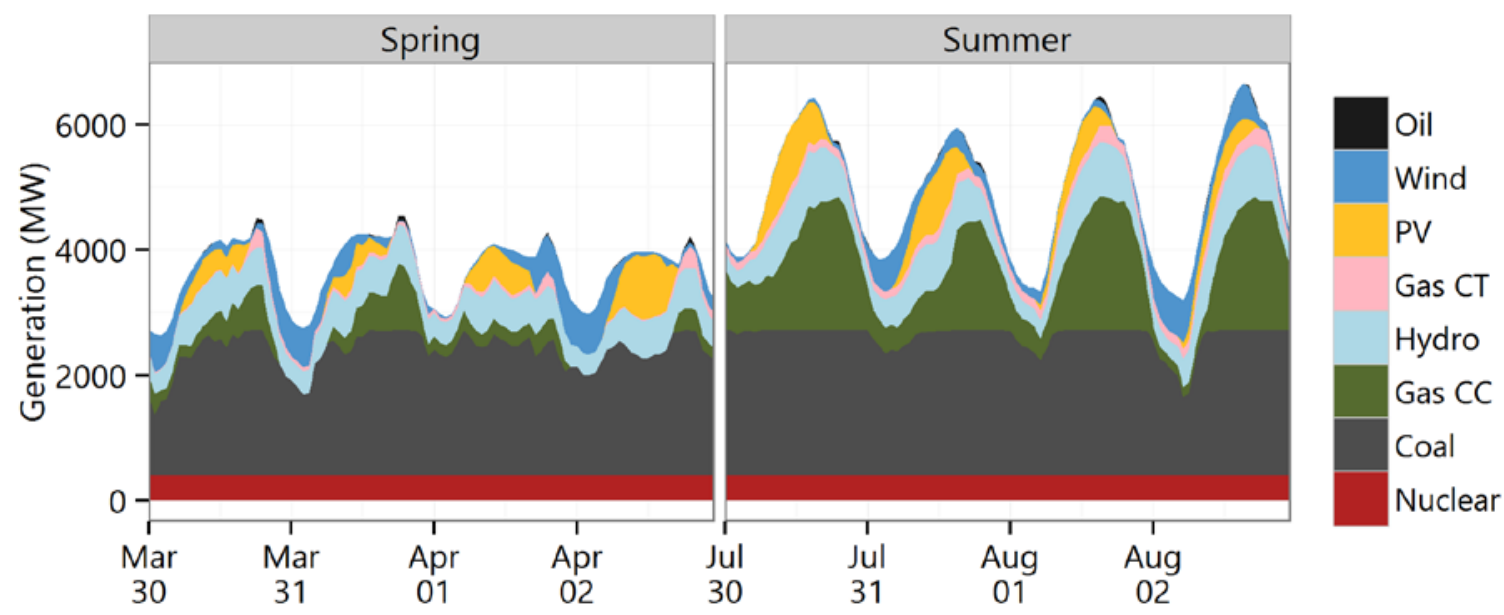

Figure 1. Dispatch of RTS-GMLC test system used in this analysis, for four days in the summer and spring

The test system contains three classes of ancillary services: spinning contingency reserves, flexibility reserves, and regulating reserves. Spinning contingency reserves are calculated hourly as 3\% of total system load and must be supplied within 10 minutes. Almost any partially loaded generator, constrained by its ramp rate, can provide spinning contingency reserves. Hydropower generators - which are modeled as fixed-profile, non-dispatchable resources - cannot provide contingency or any other class of reserve. The requirements of regulation and flexibility reserves are based on the statistical variability of wind and PV generation, as described in [23, 24]. Both regulation and flexibility are modeled as separate upward and downward resources. All generators that can provide contingency reserves can also contribute to the flexibility requirements. Regulation reserves can be provided by the same generator classes, with the exception of natural gas fired combustion turbines (CTs). Regulation reserves vary by hour but are on average $1.2 \%$ of load and must be supplied within five minutes. Flexibility reserves also vary in time and are on average $0.8 \%$ of load and must be supplied within 20 minutes. PLEXOS models only the provision of each of these services, not the actual deployment (or real energy use) of any class of reserve. The implications of this shortcoming are discussed in Section 4.1.

\subsection{General Approach to Incorporating CSP-TES in a Production Cost Model}

Production cost models typically incorporate wind and PV as fixed-input profiles. These profiles are generated by an external model that turns time-series wind-speed profiles and solar irradiance into electricity output profiles $[25,26]$. The PCM then uses these output profiles as part of a larger generation fleet to minimize production costs while maintaining reliability. However, CSP-TES systems, which are more complex than PV or wind technologies, require more detailed modeling. An intermediate process is required to simulate the conversion of direct normal irradiance into electricity. Moreover, the actual dispatch decision of when and how the CSP-TES plant operates must be performed by the PCM, as determined by the system needs. Our approach is illustrated in Figure 2. There are two major steps, which are described in detail in Sections 2,3 and 2.4. The first is the generation of hourly available electricity profiles, using a CSP simulation tool, NREL's System Advisor Model (SAM) [27, 28]. The second is incorporating this electricity-availability profile - along with many of the particular CSP-TES parameters, including configuration - into a PCM such as PLEXOS. 


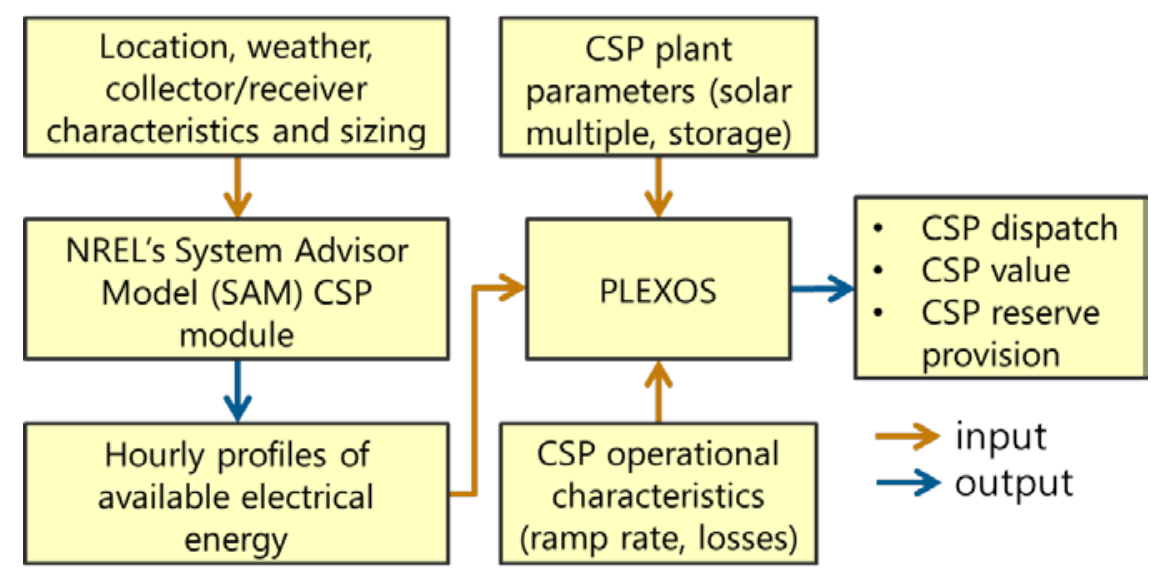

Figure 2. Generalized method for incorporating CSP-TES in a PCM

\subsection{Solar Electricity Availability from SAM}

There are several types of CSP-TES plants, typically characterized by the solar field, receiver type, and heat-transfer medium [28]. Figure 3 illustrates an indirect molten salt CSP-TES plant including four basic components:

- A collector field that focuses solar energy onto a receiver

- A solar receiver that absorbs incident solar energy and transfers that energy to a heat-transfer fluid (HTF) flowing through the receiver

- TES that stores energy from the HTF

- A power block that converts the thermal energy into electrical energy.

The solar multiple (SM) is an important consideration in CSP-TES design. It is the ratio of the thermal power available from the collector field and receiver under reference conditions (commonly solar noon on the summer solstice) to the thermal input required to operate the power block at full load [2]. Increasing the SM increases the size of the solar field relative to the power block and thus increases the amount of solar energy available to the power block. Generally, plants with larger SMs have larger capacity factors owing to their increased solar energy, which leads to a more-constant plant output. The small power block associated with a higher SM forces a plant to store energy even during periods of high energy value. However, plants with lower SMs can have more flexibility in when to dispatch their solar energy [29]. 


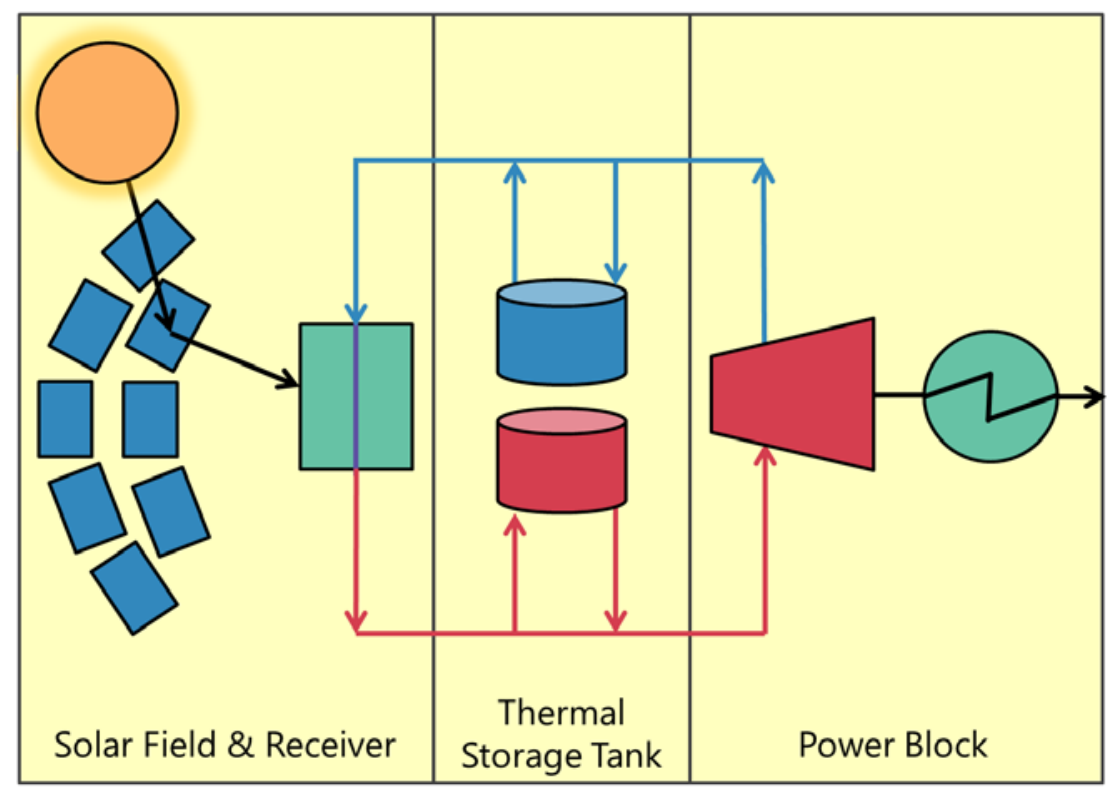

Figure 3. Four components of an indirect molten salt CSP-TES plant

Solar energy reflects off of solar collectors onto the receiver, which uses an HTF to transfer thermal energy to the molten salt in the thermal storage tank. The molten salt then powers a steam turbine and generator.

SAM estimates CSP-TES plant productivity using hourly or subhourly historical weather data and a set of component submodels for the collector field, solar receiver, TES, and power block that are evaluated in a time series of hourly or subhourly intervals. At each interval, the solver evaluates all component models, determines operational states, and balances mass flows, energy flows, and inlet/outlet temperatures. For the purposes of interfacing with a PCM such as PLEXOS, the component models can be conceptually segregated into those associated with the generation of thermal energy from incident solar energy in any period (collector and receiver) and those associated with storing and/or dispatching thermal energy to generate electricity (TES and power block). The collector and receiver submodels in SAM account for hourly insolation, weather conditions, collector field performance, receiver startup requirements, HTF mass flow rates to achieve design-point inlet and outlet temperatures, and receiver/piping thermal losses. Evaluation of these submodels provides an hourly profile of thermal energy available from the solar receiver ( $Q_{\text {thermal }}$ ) given a specified collector field sizing, location, and collector/receiver design and operational characteristics. This thermal energy is converted to design-point electrical-equivalent energy ( $I_{t}$ in Section 2.4 ) via multiplication by a design-point power block efficiency $\left(\eta_{\text {des }}\right)$ and provides a time-varying electrical-equivalent inflow to the PLEXOS storage reservoir.

All specifications regarding the storage and power block portions of the CSP-TES plant that may affect or be affected by plant dispatch are delegated to the PCM. These include power block partload efficiency, startup losses and costs, ramping constraints, and TES capacity and losses, which are detailed in Section 2.4. Thus, the operational characteristics of the power block and TES within the SAM simulation are inconsequential, provided the selected values do not constrain operation of the collector field or receiver. To this end, an artificially large TES capacity is implemented in SAM with negligible TES losses. This stipulation is designed to ensure the thermal output of the receiver $\left(Q_{\text {thermal }}\right)$ is never curtailed owing to insufficient 
storage. Excess energy can be "spilled" (or curtailed) in PLEXOS if the actual TES capacity is insufficient to accept the provided inflow.

Operation of the CSP-TES plant incurs parasitic electrical requirements associated with (1) collector tracking, (2) pumping HTF through the receiver, (3) pumping HTF through the TES and power block, and (4) operating the Rankine cycle condenser. All fixed parasitic loads and parasitic loads arising solely from collector field and receiver operation are aggregated into an hourly profile (shown in the next section as $E$ ), which is independent of power block operation and implemented as an additional load that must be satisfied within PLEXOS. This parasitic load is calculated under the assumptions above that prevent curtailment of the receiver thermal output, and they thus might be a slight overestimate of actual electrical requirements in cases with an undersized TES or power block. A linearized approximation of parasitic loads associated with power block operation can be incorporated in PLEXOS as a component of the part-load efficiency curve (referred to as $\eta\left(P_{t}\right) \eta\left(P_{t}\right)$ in the following section).

In the SAM simulation of the CSP-TES plant, the specified SM, power block capacity, and design-point power block efficiency govern the receiver design-point thermal rating, which in turn controls the size and layout of the solar field. The thermal energy produced by the solar field and receiver ( $Q_{\text {thermal }}$ ) and the corresponding electrical-equivalent inflow to the PLEXOS storage reservoir $\left(I_{t}\right)$ depend only on this final collector/receiver configuration, and not intrinsically on the SM or power block sizing used to create it. Thus, modifications to the SM can be accomplished by either (1) fixing the power block capacity and varying the collector/receiver sizing in SAM or (2) fixing the collector/receiver sizing in SAM and varying the power block capacity in PLEXOS. In the following analysis, we implement a 200-MW CSP-TES plant (using the molten salt tower module in SAM) with a SM of 1.6.

\subsection{Modeling CSP-TES in PLEXOS}

The electrical equivalent of thermal energy from SAM serves as the time-varying energy inflow into the storage reservoir of the CSP-TES plant. The tank then fuels the power block portion of the CSP-TES plant with solar energy. The energy balance on the thermal energy tank at time $t$ is described in Equation (1):

$$
\operatorname{Vol}_{t}=\mathrm{Vol}_{t-1}+I_{t}-O_{t}-S_{t}
$$

subject to:

$$
0 \leq \mathrm{Vol}_{t} \leq h P_{\max }
$$

where $\mathrm{Vol}$ is the volume of the thermal storage tank in megawatt-hours (MWh), $I$ is electricalequivalent energy inflow from the solar field, $O$ is energy supply from the thermal storage tank to the power block, $S$ is spillage from the tank that may be needed to meet the constraint in Equation (2), $h$ is the number of hours of thermal storage in the tank, and $P_{\max } P_{\max }$ is the rated generating capacity of the power block. 
When the energy from the storage tank $(O)$ flows to the power block for generation, Equation (3) defines the amount of power produced. Note that the SM parameter, discussed in Section 2.3, determines the ratio of inflow from the solar field $(I)$ to the power output of the plant $\left(P_{t}\right)$ :

$$
P_{t}=\eta\left(P_{t}\right) O_{t}-u_{s, t} L-E
$$

subject to:

$$
\begin{aligned}
& u_{p, t} 0.15 P_{\max } \leq P_{t} \leq u_{p, t} P_{\max } \\
& u_{p, t} \leq u_{p, t-1}+u_{s, t} \\
& u_{s, t}+u_{p, t-1} \leq 1 \\
& P_{t-1}-\frac{0.1}{\min _{\operatorname{0.1}}} P_{\max } \times 60 \mathrm{~min} \leq P_{t} \leq P_{t-1}+\frac{0.1}{\min } P_{\max } \times 60 \mathrm{~min} \\
& P_{\mathrm{t}-1}-\frac{0.1}{\min } P_{\max } \times 60 \min \leq P_{t} \leq P_{t-1}+\frac{0.1}{\min } P_{\max } \times 60 \min
\end{aligned}
$$

where $u_{s, t}$ is a binary variable indicating whether the plant started up at time $\mathrm{t}, u_{p, t}$ is a binary variable indicating whether the plant is operating at time $\mathrm{t}, L$ is the hourly plant startup loss shown in Equation (8), $E$ are hourly fixed parasitic loads and parasitic loads arising from collector and receiver operation, and $\eta\left(P_{t}\right)$ is a piecewise linear efficiency function that depends on plant output, $P_{t}$, as shown in Equations (9)-(12).

The efficiency curve is based on the part-load heat rate of similar steam turbines in the western United States [30]. Equation (4) specifies the operating range of the turbine, while Equation (7) specifies the ramp rate of the plant. It is sufficiently high, in this case, that (7) is not binding in hourly economic dispatch but is relevant for response time for the provision of reserves, as discussed in Section 4.1.

$$
\begin{aligned}
& L=0.2 P_{\text {max }} \\
& \eta\left(P_{t}\right)=\frac{0.413 P_{t}}{P_{\max }}+0.772 \text { for } 0.15 P_{\max } \leq P_{t}<0.33 P_{\max } \\
& \eta\left(P_{t}\right)=\frac{0.232 P_{t}}{P_{\max }}+0.831 \text { for } 0.33 P_{\max } \leq P_{t}<0.6 P_{\max } \\
& \eta\left(P_{t}\right)=\frac{0.096 P_{t}}{P_{\max }}+0.931 \text { for } 0.6 P_{\text {max }} \leq P_{t}<0.8 P_{\text {max }} \\
& \eta\left(P_{t}\right)=\frac{0.050 P_{t}}{P_{\max }}+0.950 \text { for } 0.8 P_{\max } \leq P_{t}<P_{\max }
\end{aligned}
$$




\section{Value of Energy from CSP-TES}

\subsection{Energy Value from First CSP-TES Plant}

Production cost modeling tools, such as PLEXOS, simulate the optimal unit commitment and economic dispatch of a system. They minimize total generation cost, subject to the many constraints of the system. In this case, total generation cost is the sum of several components: fuel cost, startup and shutdown costs, and variable operation and maintenance costs.

We determine the energy value of CSP-TES by completing one annual run without CSP-TES and comparing the total generation cost to an annual run with CSP-TES. The difference between the two is the direct result of adding CSP-TES to the system. Because CSP-TES has zero fuel cost, it displaces more costly generation. The value of CSP-TES is then the reduction in cost resulting from the displaced energy. Figure 4 indicates the dispatch of CSP-TES energy as determined by the PLEXOS model for four days in two seasons. Less solar energy is available during spring days, meaning less CSP-TES energy is dispatched then. In both seasons, the CSPTES plant is especially used to provide energy during the peak demand part of the day: late afternoon and early evening. Note that to determine solely the energy value of CSP-TES, we do not allow it here to provide ancillary services.

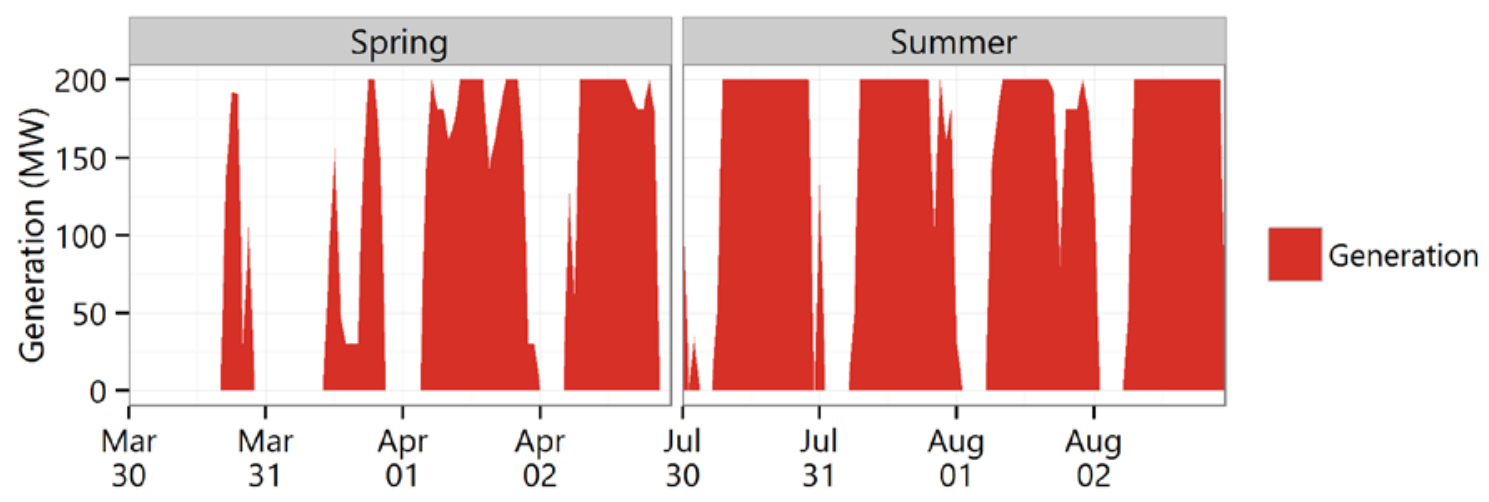

Figure 4. Optimized CSP-TES dispatch from the PLEXOS model

The base case run with no CSP-TES has an annual total generation cost of $\$ 792.9$ million. Adding a 200-MW CSP-TES plant supplying 912.5 gigawatt-hours (GWh) of annual energy reduces the generation cost to $\$ 748.1$ million. Therefore, the annual value of energy from the CSP-TES plant is $\$ 44.8$ million, or $\$ 49.1 / \mathrm{MWh}$. About $90 \%$ of the savings results from avoided fuel use, with the rest coming from avoided startup and shutdown costs. Note that this avoided generation value includes only avoided operational costs and does not consider initial capital, operating costs, or other fixed costs.

\subsection{Energy Value from Additional CSP-TES Capacity}

The initial addition of $200 \mathrm{MW}$ of CSP-TES generation capacity has a quantifiable impact on reducing total generation cost, but, as more CSP-TES is added to the system, each incremental addition yields less benefit. Other studies have shown similar results when incrementally adding more traditional PV to a system [31]. Figure 5 shows this trend when a second and third 200MW CSP-TES plants are added, which brings total CSP-TES capacity to $600 \mathrm{MW}$. As discussed above, the first plant provides an annual value of $\$ 44.8$ million. The second plant provides $\$ 41.7$ 
million while generating $893 \mathrm{GWh}$, and the third plant provides $\$ 38.5$ million while generating $897 \mathrm{GWh}$ over the year. Thus, the second and third plants exhibit reductions in the overall cost benefit of $7 \%$ and $14 \%$, respectively, compared with the first addition.

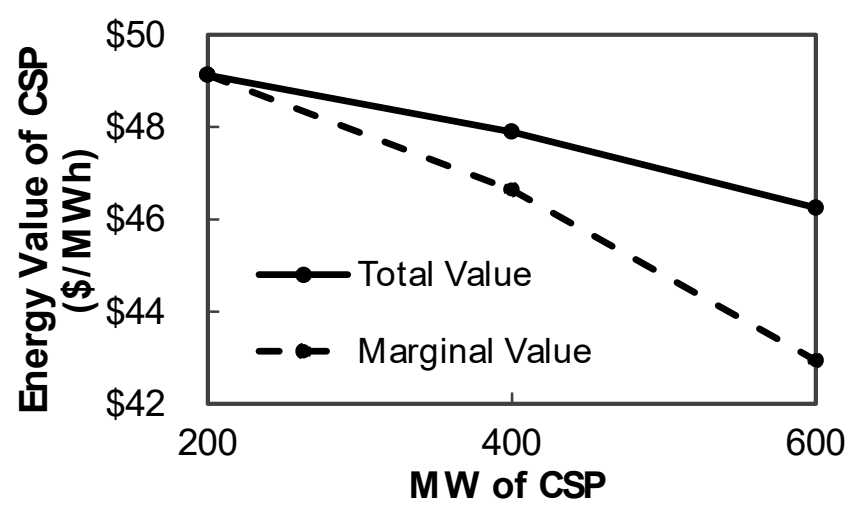

Figure 5. Decrease in energy value of CSP-TES with subsequent additions of capacity

Although the average value of each MWh from CSP-TES remains high after three subsequent CSP-TES additions, the marginal value of each megawatt-hour from the last (third) 200-MW plant is only $\$ 42.9 / \mathrm{MWh}$, compared with $\$ 49.1 / \mathrm{MWh}$ from the first 200-MW plant.

The decline in benefit occurs because the first CSP-TES plant uses its dispatchable and lowmarginal-cost energy to displace the most expensive fuels. The subsequent plants then displace slightly less-costly fuels, providing less energy value, overall. Figure 6 shows the fraction of other types of generation that the CSP-TES plants displace. The figure indicates that the first CSP-TES plant displaces a larger fraction of more expensive natural gas-fueled plants. The second and third CSP-TES plants displace a higher fraction of less-expensive coal-fired plants, leading to a decline in value. Analyzing the decline in energy value is another benefit of using PCMs to value CSP-TES. Price-taker models cannot evaluate the impact of increasing CSP-TES capacity because they assume a static system.

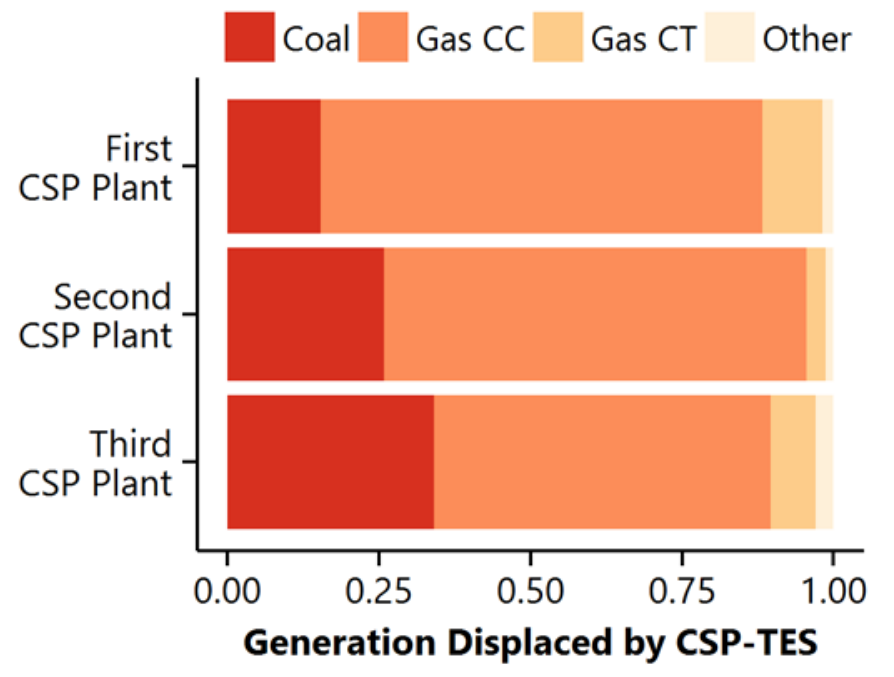

Figure 6. Displacement of generation mix by CSP-TES changes with each capacity addition

$\mathrm{CC}=$ combined cycle; $\mathrm{CT}=$ combustion turbine

The first addition displaces the largest share of the most expensive natural gas fuel.

The third addition displaces less natural gas fuel and more of the less-expensive coal fuel. 


\section{Value of Reserves from CSP-TES}

\subsection{Implementation of Constraints in Model}

Another potential value stream for CSP-TES is ancillary service or reserve markets. Because CSP-TES is a dispatchable resource, it can operate at part load and provide operating reserves, including contingency and regulating reserves. As with any thermoelectric power plant, many factors can affect the ability of CSP-TES to provide reserves. Response time (or ramp rate), available capacity, and part-load efficiency all define a unit's ability and cost for providing reserves [32]. However, the response of CSP-TES is limited by solar resource and TES tank size, in addition to the parameters mentioned above. For instance, a CSP-TES plant may have sufficient response time and available capacity to provide ancillary services, but it could still be restricted by insufficient insolation or stored energy. Furthermore, CSP-TES's provision of reserves may be inhibited by a lack of precedence, installed control equipment, or operating experience.

The fact that CSP-TES is an energy-limited resource makes modeling its ability to provide reserves challenging in models, because many simulations only consider the provision of reserves, not the deployment of any actual energy associated with being called on to supply those reserves. For conventional fossil-fuel-fired power plants, this distinction would rarely cause problems, because plant operators can simply consume more or less fuel if they are called to provide upward or downward reserves. However, the PCM may determine CSP-TES as the lowest-cost source of upward reserves without considering that the energy available to the CSPTES plant is determined by weather. For instance, the CSP-TES plant may be providing 100 MWh of upward reserves when it only has $20 \mathrm{MWh}$ of stored energy available. (We use the nomenclature MWh to indicate a MW of capacity available for one hour, as opposed to a MWh which is a unit of actual energy delivered.) If the plant were called on to deploy the reserve capacity, the plant may be unable to respond adequately. Under certain conditions, the CSP-TES plant may have sufficient stored energy available, but it could be scheduled to use that stored energy later in the day. Deploying upward reserves would then deplete the storage earlier than planned.

Many recent analyses do not attempt to accurately capture the reserve provision of energylimited resources. However, a failure to account for the fact that holding reserve services often results in the expenditure of real energy may misrepresent the actual role a given technology (e.g., CSP-TES) may play. However, there are multiple ways to constrain the reserve provision of energy-limited resources in grid models. First, a dispatch-to-contract ratio can be implemented in which the plant is obligated to provide (in real energy) a certain percentage of the reserves it is allotted. Second, the CSP-TES plant can be required to provide equal upward and downward reserves in every time step, which assumes that regulating reserve is an energy-neutral service over the multi-hour period of economic dispatch [33]. In that case, CSP-TES may not be allowed to provide spinning contingency reserves, because these reserves have only an upward component. Third, a constraint can disallow CSP-TES from providing reserves if the storage tank does not have sufficient energy. We use the third option and require that the plant be able to provide 0.5 hour of real energy per unit of reserve capacity held. This means CSP-TES could respond to a continuous regulation "up" signal, or it could provide additional energy during a 
contingency event for up to 30 minutes, as shown in Equation (15). The ability to provide reserves is then governed by Equations (13)-(20):

$$
\begin{aligned}
& P_{t}+p_{t, \text { reg_up }}+p_{t, \text { flex_up }}+p_{t, \text { spin }} \leq u_{p, t} P_{\max } \\
& P_{t}-p_{t, \text { reg_down }}-p_{t, \text { flex_down }} \geq u_{p, t} 0.15 P_{\max }
\end{aligned}
$$

subject to:

$$
\begin{aligned}
& 0.5\left(p_{t, \text { reg_up }}+p_{t, \text { flex_up }}+p_{t, \text { spin }}\right) \leq \mathrm{Vol}_{t} \\
& p_{t, \text { reg_up }} \leq \frac{0.1}{\min } P_{\max } \times 5 \mathrm{~min} \\
& p_{t, \text { reg_down }} \leq \frac{0.1}{\min } P_{\max } \times 5 \mathrm{~min} \\
& p_{t, \text { flex_up }} \leq \frac{0.1}{\min } P_{\max } \times 20 \mathrm{~min} \\
& p_{t, \text { flex_down }} \leq \frac{0.1}{\min } P_{\max } \times 20 \mathrm{~min} \\
& p_{t, \text { spin }} \leq \frac{0.1}{\min } P_{\max } \times 10 \min
\end{aligned}
$$

where $p_{t, r e g \_u p}$ is the regulation up provision in time $t, p_{t, r e g \_d o w n}$ is the regulation down provision in time $t, p_{t, f l e x}$ wp is the upward flexibility provision in time $t, p_{t, f l e x}$ down is the downward flexibility provision in time $t$, and $p_{t, \text { spin }}$ is the spinning contingency provision in time $t$.

Constraints (16)-(20) limit the amount of reserves that the plant can provide based on the response rate requirement of each reserve product ( 5 minutes for regulation, 20 minutes for flexibility, and 10 minutes for spinning contingency) and the plant's assumed ramp rate, 10\% per minute.

\subsection{Reserves Value from First CSP-TES Plant}

We quantify the value of a CSP-TES plant in providing reserves by completing one annual run without CSP-TES providing reserves and then comparing the total generation cost to an annual run with CSP-TES providing reserves. Any difference between the two (including production costs and the hourly dispatch of the CSP-TES plant) is the direct result of allowing CSP-TES to provide reserve services to the system.

A 200-MW CSP-TES plant providing only energy results in an annual total generation cost of $\$ 748.1$ million, as discussed above. When this CSP-TES plant is allowed to provide reserves, subject to the constraints above, the total annual generation cost is $\$ 745.3$ million. This indicates 
an annual value of $\$ 2.8$ million from reserves. Because the CSP-TES plant generates $888.7 \mathrm{GWh}$ of annual energy, the value of the reserve service is $\$ 3.1 / \mathrm{MWh}$. In other words, the ability of CSP-TES to provide reserves adds \$3.1/MWh to the original energy value of \$49.1/MWh, bringing the total value to $\$ 52.2 / \mathrm{MWh}$. Allowing CSP-TES to provide reserves adds value because these reserves displace reserves provided by more expensive sources. Note that the increase in value (about 6\%) is lower than the increase suggested by previous studies $[11,34]$, likely resulting in part from the extra constraints added to the energy-limited CSP-TES plant (Equation 15). Furthermore, ancillary service prices from PCMs are often much lower than observed historical prices [32]. Thus, price-taker analysis might show higher values associated with the provision of ancillary services.

Figure 7 illustrates the energy and reserve dispatch of a CSP-TES plant from the PLEXOS model for the same eight days as in Figures 1 and 3. For contrast, Figure 3 shows the dispatch of the CSP-TES plant in providing only energy, whereas Figure 7 shows the plant co-optimized for energy and reserves. The energy dispatches of the two are generally similar; however, particularly in the spring, the CSP-TES plant turns on for more hours of the day at a lower dispatch point to provide reserves. During the spring dispatch period, the CSP-TES plant is reserving some energy in storage specifically to be able to provide reserves while still adhering to the stored energy constraint in Equation (15).

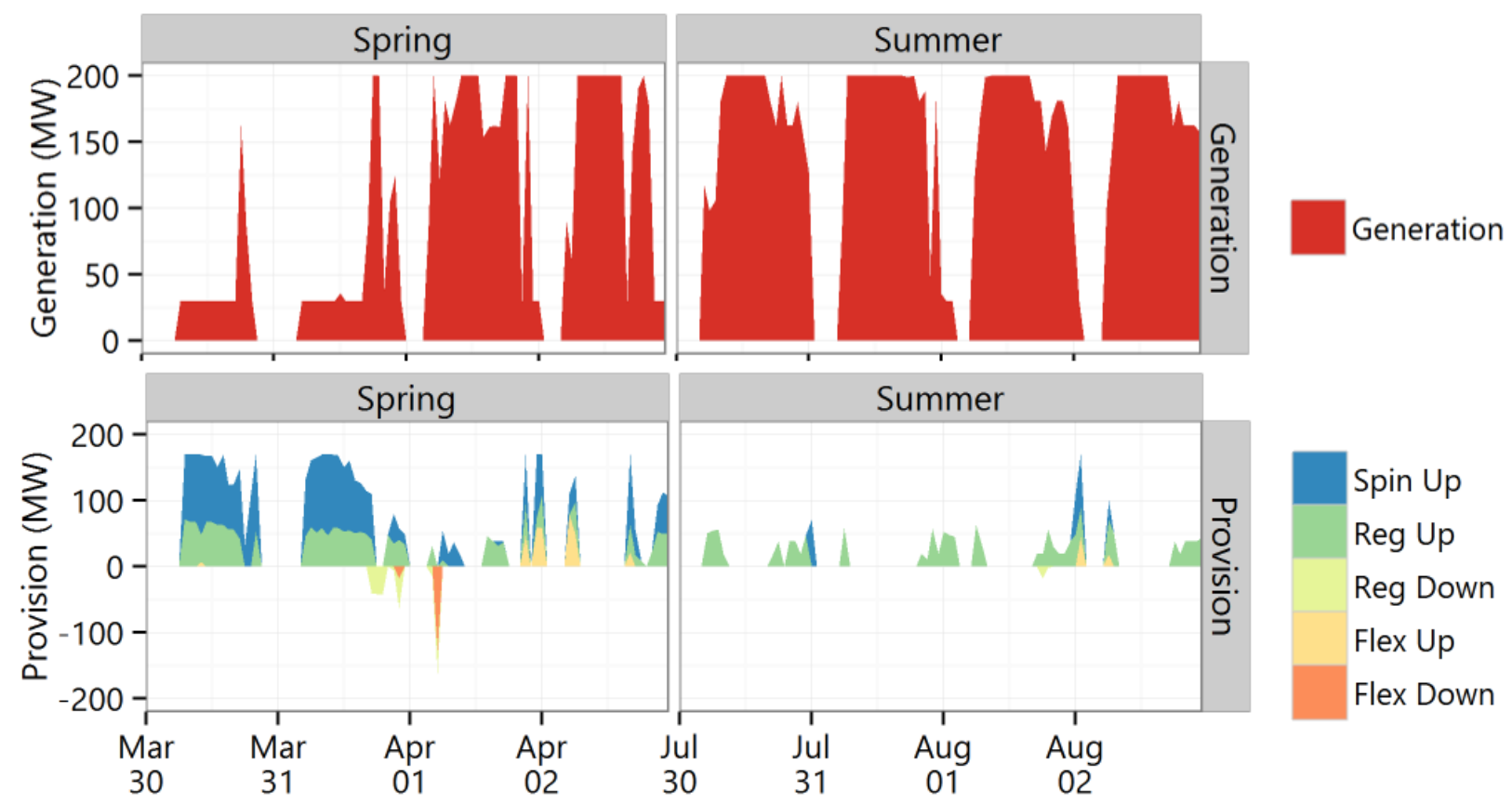

Figure 7. Energy and ancillary service dispatch for CSP-TES plant as determined by PLEXOS model 


\subsection{Reserves Value from Additional CSP-TES Capacity}

As more CSP-TES is added to the system, each incremental addition yields less benefit in terms of reserve value. Providing reserve services adds about $\$ 2.8$ million of annual value from a 200 MW CSP-TES plant compared with providing energy only, as shown above. Allowing a second 200-MW CSP-TES plant to provide ancillary services (along with energy) provides an additional $\$ 2.1$ million in annual value. The reserves value from a third CSP-TES plant of the same size is $\$ 0.9$ million annually. Figure 8 illustrates this result by showing the additional value (in units of $\$ / \mathrm{MWh}$ ) of providing reserves. The marginal value of reserves drops by about $68 \%$ from the first to the third plant (compared with a $12 \%$ drop in energy value) because of the limited system reserve requirements.

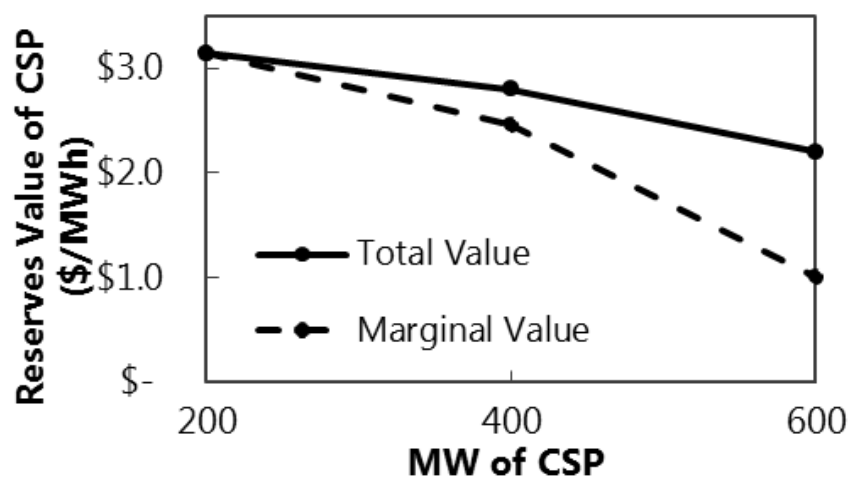

Figure 8. Decreases in value of reserve services provided by CSP-TES with subsequent addition of CSP-TES capacity

Although the average of CSP-TES reserves is worth $\$ 2.2 / \mathrm{MWh}$ after adding three plants, the reserves provided by the third $200 \mathrm{MW}$ of CSP-TES capacity are worth only \$1.0/MWh.

In real-world operations, the ability of CSP-TES to provide reserves might be more constrained than modeled here. For instance, even in the case with only $200 \mathrm{MW}$ of CSP-TES in the system, CSP-TES is providing just over $20 \%$ of all system reserves, including close to $50 \%$ of the upward regulation requirements. With $600 \mathrm{MW}$ of CSP-TES in the system, the reserve provision of CSP-TES increases to almost $40 \%$ of system reserves and over $60 \%$ of upward regulation requirements. Furthermore, CSP-TES provides $100 \%$ of the reserve requirement for upward regulation reserves in $40 \%$ of hours in the 200 -MW case and $55 \%$ of hours in the 600 -MW case. The ability of CSP-TES to provide these levels of reserve services would depend on market rules allowing an individual generator to provide a large fraction of a reserve product. 


\section{Summary}

In this report, we describe a useful approach for accurately representing the dispatchability and weather-dependence of CSP-TES in production cost models. We also discuss the challenge of properly representing the ability of CSP-TES to provide reserves because of the technology's energy-limited nature. We apply our modeling methods to illustrate how the value of CSP-TES providing energy and ancillary services can be captured together and independently. We also demonstrate how the marginal value of different generation capacities can be captured. This approach can be applied to most commercial, academic, and open-source production cost models, so CSP-TES can be appropriately valued in power system planning studies, which may be imperative to the future of the technology. 


\section{References}

[1] U.S. Department of Energy, SunShot Vision Study, Chapter 5: Concentrating Solar Power: Technologies, Cost, and Performance (Golden, CO: National Renewable Energy Laboratory, NREL/BK-5200-47927, 2012).

[2] C. Turchi, Z. Ma, T. Neises, M. Wagner, "Thermodynamic Study of Advanced Supercritical Carbon Dioxide Power Cycles for High Performance Concentrating Solar Power Systems," in ASME $20126^{\text {th }}$ International Conference on Energy Sustainability (2012).

[3] International Energy Agency, Medium-Term Renewable Energy Market Report 2016 (2016).

[4] M. Mehos, C. Turchi, J. Jorgenson, P. Denholm, C. Ho, and K. Armijo, On the Path to SunShot: Advancing Concentrating Solar Power Technology, Performance, and Dispatchability (Golden, CO: National Renewable Energy Laboratory, NREL/TP-550065688, 2016).

[5] J. Lilliestam, M. Labordena, A. Patt, and S. Pfenninger, "Empirically Observed Learning Rates for Concentrating Solar Power and Their Responses to Regime Change," Nature Energy 2 (June 2017).

[6] R. Sioshansi and P. Denholm, "The Value of Concentrating Solar Power and Thermal Energy Storage," IEEE Transactions on Sustainable Energy 1, no. 3 (October 2010): 173-183. DOI: 10.1109/TSTE.2010.2052078.

[7] P. Denholm, Y-H Wan, M. Hummon, and M. Mehos, "The Value of CSP with Thermal Energy Storage in the Western United States," Energy Procedia: SolarPACES 2013. 49 (2014): 1622-1631.

[8] J. Jorgenson, P. Denholm, and M. Mehos, Estimating the Value of Utility-Scale Solar Technologies in California under a 40\% Renewable Portfolio Standard (Golden, CO: National Renewable Energy Laboratory, NREL/TP-6A20-61685, 2014).

[9] S. Wagner and E. Rubin, "Economic Implications of Thermal Energy Storage for Concentrated Solar Power," Renewable Energy 61, Issue C (2014).

[10]S. Madaeni, R. Sioshansi, and P. Denholm, "How Thermal Energy Storage Enhances the Economic Viability of Concentrating Solar Power," Proceedings of the IEEE 100, no. 2 (February 2012).

[11]G. He, X. Chen, C. Kang, and Q. Xia, “Optimal Offering Strategy for Concentrating Solar Power Plants in Joint Energy, Reserve and Regulation Markets," IEEE Transactions on Sustainable Energy 7, no. 3 (July 2016): 1245-1254.

[12]H. Pousinho, J. Esteves, V. Mendes, M. Collares-Pereira, and C. Pereira Cabrita, “Bilevel Approach to Wind-CSP Day-Ahead Scheduling with Spinning Reserve under Controllable Degree of Trust," Renewable Energy 86, Issue C (2016). 
[13]R. Dominquez, L. Baringo, and A.J. Conejo, “Optimal Offering Strategy for a Concentrating Solar Power Plant," Applied Energy 98 (2012): 316-325.

[14]M. Petrollese, D. Cocco, G. Cau, and E. Coglani, "Comparison of Three Different Approaches for the Optimization of the CSP Plant Scheduling," Solar Energy 150 (2017): 463-476.

[15]A. Mills and R. Wiser, An Evaluation of Solar Valuation Methods Used in Utility Planning and Procurement Processes (Berkeley, CA: Ernest Orlando Lawrence Berkeley National Laboratory, LBNL-5933E (December 2012).

[16]CSP Alliance, The Economic and Reliability Benefits of CSP with Thermal Energy Storage: Literature Review and Research Needs (September 2014).

[17]B. Brand, A Boudghene Stamboudli, and D. Dejli, “The Value of Dispatchability of CSP Plants in the Electricity Systems of Morocco and Algeria," Energy Policy 47 (2012): 321331.

[18]A. Narimani, A. Abeygunawardana, G.F. Ledwich, and G. Nourbakhsh, "Value of Concentrating Solar Power with Thermal Energy Storage in the National Electricity Market of Australia," IEEE Australasian Universities Power Engineering Conference (2016).

[19]Energy Exemplar, PLEXOS Electricity version 7.300 R04 x64 Edition [computer software], accessed July 3, 2017: http://energyexemplar.com/.

[20]C. Barrows, A. Bloom, A. Ehlen, J. Jorgenson, D. Krishnamurthy, B. McBennett, and M. O’Connell. "Modernizing the IEEE Reliability Test System," IEEE Transactions on Power Systems (Forthcoming).

[21]D. Lew, G. Brinkman, E. Ibanez, A. Florita, M. Heaney, B.-M. Hodge, M. Hummon, and G. Stark, The Western Wind and Solar Integration Study Phase 2 (Golden, CO: National Renewable Energy Laboratory, NREL/TP-5500-55588, 2013).

[22]G. Brinkman and J. Jorgenson, Low Carbon Grid Study: Analysis of a 50\% Emission Reduction in California (Golden, CO: National Renewable Energy Laboratory, NREL/TP6A20-64884, 2016).

[23]E. Ibanez, G. Brinkman, M. Hummon, and D. Lew, “A Solar Reserve Methodology for Renewable Energy Integration Studies Based on Sub-Hourly Variability Analysis," presented at the 2nd Annual International Workshop on Integration of Solar Power into Power Systems Conference, Lisbon, Portugal, November 12-13, 2012.

[24]E. Ibanez, I. Krad, and E. Ela, A Systematic Comparison of Operating Reserve Methodologies (Golden, CO: National Renewable Energy Laboratory, NREL/CP-5D0061016, 2014).

[25]C. Draxl, A. Clifton, B.-M. Hodge, and J. McCaa, “The Wind Integration National Dataset (WIND) Toolkit,” Applied Energy 151 (August 2015): 355-366. 
[26]M. Hummon, E. Ibanez, G. Brinkman, and D. Lew, Sub-Hour Solar Data for Power System Modeling from Static Spatial Variability Analysis (Golden, CO: National Renewable Energy Laboratory, NREL/CP-6A20-56204, November 2012).

[27]National Renewable Energy Laboratory, System Advisor Model Version 2016.3.14 (SAM 2016.3.14) [computer software], 2016, accessed June 2017: https://sam.nrel.gov/.

[28]M.J. Wagner, "Simulation and Predictive Performance Modeling of Utility-Scale Central Receiver System Power Plants," (M.S. thesis, Mechanical Engineering Dept., University of Wisconsin-Madison, 2008).

[29]J. Jorgenson, P. Denholm, and M. Mehos, "Quantifying the Value of Concentrating Solar Power in a Production Cost Model," in ASME $20148^{\text {th }}$ International Conference on Energy Sustainability (2014).

[30]J. Jorgenson, P. Denholm, M. Mehos, and C. Turchi, Estimating the Performance and Economic Value of Multiple Concentrating Solar Power Technologies in a Production Cost Model (Golden, CO: National Renewable Energy Laboratory, NREL/TP-6A20-58645, December 2013).

[31]P. Denholm, M. O’Connell, G. Brinkman, and J. Jorgenson, Overgeneration from Solar Energy in California: A Field Guide to the Duck Chart (Golden, CO National Renewable Energy Laboratory, NREL/TP-6A20-65023, 2015).

[32]M. Hummon, P. Denholm, J. Jorgenson, and D. Palchak, Fundamental Drivers of the Cost and Price of Operating Reserves (Golden, CO: National Renewable Energy Laboratory, NREL/TP-6A20-58491, 2013).

[33]B. Xu, Y. Dvorkin, D.S. Kirschen, C.A. Silva-Monroy, and J.A. Watson, “A Comparison of Policies on the Participation of Storage in U.S. Frequency Regulation Markets," in IEEE 2016 Power and Energy Society General Meeting, Boston, MA, July 2016.

[34]P. Denholm, Y.-H. Wan, M. Hummon, and M. Mehos, An Analysis of Concentrating Solar Power with Thermal Energy Storage in a California 33\% Renewable Scenario (Golden, CO: National Renewable Energy Laboratory, NREL/TP-6A20-58186, March 2013). 